\title{
ESTO ES TRABAJO DE MUJERES: DOS GENERACIONES EN EL SECTOR DOMÉSTICO
}

\author{
THIS IS A WOMEN'S WORK: TWO GENERATIONS IN THE DOMESTIC \\ SECTOR
}

\author{
Cristina Benlloch Doménech \\ Cristina Pérez Pérez \\ Universidad de Valencia. España/Spain \\ cristina.benlloch@uv.es \\ cristinaperez.vlc@gmail.com
}

Recibido/Received: 06/06/2010

Aceptado/Accepted: 25/07/2010

\section{RESUMEN}

El trabajo femenino en el sector doméstico ha estado invisibilizado y menospreciado durante siglos. Este artículo es el resultado de una investigación realizada con mujeres de nacionalidad española de dos generaciones que han trabajado en el sector doméstico. Se ha realizado con el fin de comprender y analizar las diferencias en este trabajo a lo largo de más de 50 años. Se trata de una investigación cualitativa que ha puesto de manifiesto que lejos de tratarse de un trabajo minoritario, muchas mujeres lo han estado realizando, y todavía lo realizan. Suponiendo, al contrario de lo que se piensa, un pilar fundamental en la economía de muchas familias, pero que se ha visto relegado al ámbito de lo irrelevante por tratarse de un trabajo "de mujeres" en el espacio "de las mujeres".

PALABRAS CLAVE

Género, historia del trabajo, generaciones domésticas, empleadas de hogar, migraciones domésticas.

\section{SUMARIO}

1. Introducción. 2. Dos generaciones de mujeres: un mismo sector. 3. Conclusiones. Bibliografía.

\begin{abstract}
Women's work in the domestic sector has been invisible and underestimated for centuries. This article is the result of an investigation realized with Spanish women of two different generations, who have worked in the domestic sector. The aim of the article is to understand and analyze differences in this kind of work within more than fifty years. It is a qualitative investigation, and it has made clear that instead of being a minority work, lots of women have carried it out, and still do. Contrary to what is thought, it means a basic mean of support for many families' finances but it has been relegated to the irrelevant for being a "women's" work in the "women's" area.
\end{abstract}

\section{KEY WORDS}

Gender, history of work, domestic generations, housework employees, domestic migrations.

\section{CONTENTS}

1. Introduction. 2. Two generations of women: the same sector. 3. Conclusions. References. 


\section{INTRODUCCIÓN}

Xiqueta, jo quant tenia la teua edad ja servia en València (Niña, yo cuando tenía tu edad ya servía en Valencia). A muchas de nosotras esta frase nos sonará muy familiar, nos la han repetido nuestras abuelas desde que éramos muy pequeñas. Recuerdo que tenía 9 años y no comprendía las palabras de mi abuela, una mujer muy arrugada que contaba historias y a veces me cantaba en francés, y después me decía jo m'haguera quedat a Francia allí anava a l'escola (Yo me hubiera quedado en Francia, allí iba a la escuela). Con el paso del tiempo comprendí la fuerza de las palabras y de su experiencia. Este trabajo está dedicado a las mujeres que siendo niñas salieron a trabajar como empleadas del servicio doméstico; y también a las mujeres que tienen 50 años y trabajan en este sector.

Estamos acostumbradas a leer que las mujeres no han trabajado, y que desde los años 70 se han incorporado de forma masiva al mercado de trabajo (Cortina, A: 1999). Si bien es cierto, que mucho del trabajo que las mujeres han realizado no se encuadra dentro de la definición del trabajo fordista: empleo a jornada completa y para toda la vida (Sennet, 2000), esto no significa que las mujeres no hayan trabajado.

Según el Ministerio de Trabajo e Inmigración, en España a finales de 2008 había más de 12.000 personas afiliadas a la Seguridad Social en régimen del hogar. De estas, sabemos que más del $95 \%$ eran mujeres. Lo cierto es que esta cifra no es más que la punta del iceberg. Muchas mujeres de nacionalidad extranjera trabajan sin alta en la Seguridad Social, y muchas mujeres autóctonas también. El objeto de este trabajo es una aproximación a la realidad de las empleadas del hogar, atendiendo a dos generaciones de mujeres que han dedicado su vida laboral al trabajo en el servicio doméstico.

Este es un sector muy estudiado, pero en el trabajo queríamos que las mujeres protagonistas nos contaran su experiencia. También queríamos darle visibilidad a un sector del que no se habla cuando se describe la economía sumergida, porque siempre se tiende a pensar en la industria del calzado (Canales; Melis,1997) o del textil (Jodar y Alòs, 1995), de los inmigrantes que trabajan de forma clandestina (Cachón, 2006). Este apunte es para darle visibilidad a un sector que totalmente feminizado y por eso, infravalorado, que no entra en los cómputos; y por el que no se movilizan los sindicatos.

Existen innumerables libros que hablan del trabajo doméstico. Sobre todo desde la década de los 90 se está escribiendo mucho de las mujeres inmigrantes que trabajan como internas en el sector doméstico. Esto se ha debido a que las mujeres españolas paulatinamente han ido dejando el sector, pero también, como señala Castelló (2009), ha crecido la demanda de trabajo en este sector. Nuestro marco de análisis será también histórico, porque queremos comparar las condiciones de vida de dos generaciones, para ello se utilizarán estudios que se han centrado en el sector, como uno del Colectivo Ioé del año 2001, en el que se hablaba de diversas generaciones de trabajadoras del sector.

La premisa central desde la que se parte según su estudio, es que la relación de las mujeres, en este caso autóctonas, con el trabajo en el sector doméstico se ha ido transformando con el tiempo. Según explican en su análisis, poco a poco se han ido ampliando, desde finales del XIX las oportunidades laborales de las mujeres. (Ioé, 2001).

Para el trabajo se identificarán las entrevistadas dentro de su generación, porque interesaba saber para el trabajo cada uno de los grupos históricos. Así pues para las mujeres que trabajaron poco después de la Guerra Civil se les identificó como G.I, y a la generación de sus hijas G.II. 
Por otra parte, nos aproximaremos a las mujeres sabiendo que este es un sector en el que se mueven muchos recursos en la economía sumergida, es decir, que se producen servicios en el sector doméstico sin cobertura social, al margen del Estado. Es importante tener en cuenta si la situación de irregularidad se produce a voluntad de la interesada o como consecuencia de una condición obligatoria por parte del empleador o la empleadora. Muchas veces estas mujeres no están en alta de la seguridad social por diversas razones: 1) porque no saben si están dadas de alta; 2) la sanidad está cubierta; 3) no tienen servicio de desempleo en el régimen de empleadas de hogar; 4) la jubilación es muy pequeña (Sánchez, 2003).

El marco de análisis, para el trabajo doméstico parte de que la situación de las mujeres, depende en buena medida de las expectativas y los intereses que se hayan creado sobre el trabajo, es decir, que las condiciones que soporten en su jornada laboral dependerán de las necesidades a cubrir (es decir, si la mujer es la cabeza de familia o su salario es complementario); del momento vital en el que se encuentren, etc. (Sánchez, 2003).

A efectos de la investigación nos interesa conocer las diferencias que se han producido en el sector en los últimos 50 años, teniendo en cuenta que este trabajo hunde sus bases en el sistema de división sexual del trabajo que relega a las mujeres a unos trabajos que considera de menos categoría, y que en parte contribuyen a la reproducción de los roles de género. El problema es, según Rollins, que en el sector doméstico se crea un sistema maternalista por el cual la trabajadora acaba ejerciendo en cierto modo el rol de madre ausente (Rollins, 1985).

Sarasúa (1994) afirmaba que es complicada la definición de este trabajo porque desde las ciencias sociales se ha entendido como trabajo en términos de asalarización y trabajo en los espacios "públicos". Nosotras hemos entendido que trabajo en el sector doméstico es el trabajo que se realiza para la reproducción del hogar en el que media una relación salarial, al margen de que exista un contrato o no. Lo que Moltó y Uriel denominan como servicios de cuidado en el marco del hogar (Moltó y Uriel, 2007).

Para la descripción del cambio que se ha producido en el trabajo de empleadas de hogar en las mujeres españolas, se realizarán historias de vida, centradas en el ámbito laboral, a mujeres que han trabajado de empleadas de hogar. Más de la mitad de ellas nacieron algunos años antes de la guerra civil, y las demás en los años de la postguerra, concretamente en la década de los 50. Las entrevistas permitirán acceder a la historia laboral de estas mujeres conociendo no sólo sus condiciones laborales, sino también las motivaciones que les llevaron a desempeñar el trabajo.

Estas dos generaciones de trabajadoras en el servicio doméstico comparten experiencias, pero también discrepancias. Unas realizaron sus trabajos en la inmediata postguerra civil, y las otras en los albores del siglo XXI.

Sin embargo, en las siguientes páginas nos acercaremos a la micro-realidad de las mujeres a las que hemos entrevistado, que han visto el sector doméstico como una forma fácil de conseguir un aporte extra para sus familias. Sabemos que la estructura familiar española, a pesar de que está cambiando, se constituía por un pater familias que era el que llevaba el sueldo a casa, y los ingresos de la mujer eran considerados secundarios (Alberdi, 1999). Sin embargo vamos a estudiar la economía desde una perspectiva de género, y mostrar que los sueldos de estas mujeres no sólo han sido una contribución, sino que han sido un pilar en la economía familiar. 


\section{DOS GENERACIONES DE MUJERES: UN MISMO SECTOR}

Es muy difícil resumir la historia laboral de estas mujeres en el sector doméstico, es una historia llena de entradas y salidas del mercado. Este sector está "generizado", porque son mayoría mujeres quienes trabajan en él. Según el Ministerio de Trabajo, más del $90 \%$ de las afiliaciones en régimen de empleada de hogar son de mujeres (MTAS).

Según investigaciones realizadas en este sector, esta situación no siempre ha sido así, sino que en el siglo XVI eran hombres quienes realizaban estas tareas en las casas de los aristócratas, hasta que apareció la figura del mayordomo y poco a poco el trabajo se fue desvalorizando a medida que se convertía en trabajo de mujeres (Ioé, 2001).

En la actualidad es un trabajo poco valorado, que las nietas de nuestras mujeres no quieren realizar y que forma parte del tipo de trabajos que ahora desempeñan las mujeres inmigrantes (Parella, 2002). En las cifras de la Seguridad Social apreciamos que las españolas afiliadas al régimen del hogar disminuyen año a año (MTAS). Aunque autoras como Castelló (2009), afirman que también se debe a que hay una demanda creciente de servicios del cuidado, y que las españolas no los pueden cubrir todos. Moltó y Uriel coincidirían en que existe una demanda creciente de los servicios del cuidado, debido a que las mujeres están saliendo al mercado laboral y contratan a otras mujeres para que realicen el trabajo que antes realizaban ellas (Moltó y Uriel, 2007). Y esto es producido porque en lugar de realizar un reparto de tareas en la familia cuando la mujer sale al mercado laboral de forma continua, se externaliza, por la falta de corresponsabilidad (Bustelo y Perterson, 2005).

Lo que hemos escuchado en las entrevistas de nuestras informantes es que, en el momento actual, las hijas de la segunda generación de mujeres, que todavía trabajan en el cuidado, afirman que sus hijas no van a seguir haciendo lo mismo. Por ejemplo, el caso de una mujer de la Generación I (G.I): su madre se fue de interna a una casa, a consecuencia de la escasez de la guerra; y también emigró a Francia buscando una casa dónde servir; ella [Generación II. (G.II)] empezó planchando, aunque lo dejó cuando se casó; montó un pequeño negocio con su marido, que cerraron durante la crisis de los 90 . Esta mujer, en la actualidad se ha incorporado al sector del cuidado porque hace unos años que su marido se quedó sin empleo. La hija una de las mujeres de la Segunda Generación tiene estudios superiores, y si bien ha trabajado durante sus estudios, no lo hizo como empleada de hogar. Este recorrido de vida laboral, es según el Colectivo Ioé (2001b), el prototipo de ciclo que ha seguido el trabajo en el sector doméstico en este país.

Esta tercera generación, no valora el trabajo que realizan sus madres, según el mismo estudio citado (Ioé, 2001b), y se van a otros sectores con mayor prestigio social, a pesar de que la temporalidad es mayor, y el sueldo menor.

\section{El contexto jurídico}

Antes de conocer las condiciones personales y laborales de las mujeres, tenemos que analizar las condiciones jurídicas del régimen del hogar, de esta forma seremos capaces de comprender la situación en la que se encontraban y se encuentran las mujeres encuadradas en este régimen y entenderemos mejor las decisiones que han tomado.

Durante muchos años, el servicio doméstico fue regulado por el Derecho Civil y no por el Código del trabajo (pese a un breve período en 1931 con la Ley de Contratos de Trabajo que finalizó a los seis días cuando la Ley de Jurados Mixtos volvió a situarlo dentro del 
Derecho Civil). Durante la Segunda República fue incluido en el sistema nacional de colocación y el convenio internacional sobre seguro de enfermedad, pero se mantuvo al margen de normas sobre jornada máxima, accidentes de trabajo, descanso dominical o seguro de desempleo (Ioé, 2001b)

Durante toda la dictadura franquista la actividad siguió regulada bajo las disposiciones de la jurisdicción Civil. Poco a poco, en esta época, fue incorporándose progresivamente al sistema de la Seguridad Social, pero con grandes diferencias con respecto al Régimen General del Seguro de Enfermedad justificadas por el marco ideológico asentado en el modelo de familia cristiana.

Fue en 1969 cuando se creó el Régimen Especial de la Seguridad Social para el Servicio Doméstico, gestionado por el Ministerio de Trabajo a través de una Mutualidad Nacional de empleados de Hogar, bajo la influencia de la Sección Femenina. Sin embargo, continuaron las desigualdades respecto a los trabajadores del Régimen General. En este régimen especial, se incluyó a todo español mayor de 14 años que trabajase exclusivamente como servidor doméstico para uno o varios jefes de familia, desarrollando sus labores en el hogar familiar, y percibiera a cambio una retribución monetaria.

Con los inicios de la democracia pronto se estableció en la Ley de Relaciones Laborales de 1976 la necesidad de regular la relación laboral del "servicio del hogar familiar". Se fijó un plazo de dos años para hacerlo. Este plazo no se cumplió. De hecho, el proceso que llevó a la regulación no fue lineal ni ininterrumpido y numerosas propuestas para ello surgieron tanto de sindicatos como de partidos políticos. Por fin, en 1985 se promulgó el Real Decreto 1424 "regulador de la relación laboral de carácter especial del Servicio del hogar familiar". La norma reconoce como relación laboral el trabajo en hogares familiares, pero con carácter especial. Este carácter específico deriva de los hogares como ámbito donde se realiza el servicio, porque los hogares tienen un estatuto jurídico especial como espacio privilegiado de ejercicio de los derechos fundamentales relacionados con la intimidad. De esta forma, se argumenta este carácter basándose en la protección de los hogares familiares frente a la "invasión" por parte de la legislación laboral, y se da una gran importancia a la "mutua confianza" entre las partes. Esto provoca, por ejemplo, que se impongan restricciones a la Inspección de Trabajo, que habrá de salvaguardar los derechos de inviolabilidad del domicilio así como respetar la intimidad personal y familiar.

Hoy en día, los trabajadores comprendidos dentro del campo de aplicación del Régimen Especial de Empleados de Hogar, son los que se dedican a servicios exclusivamente domésticos para uno o varios titulares del hogar familiar, siempre que estos servicios sean prestados en la casa que habite el titular del hogar familiar y que perciban un sueldo o remuneración de cualquier clase. Están incluidos los trabajos de guardería, jardinería, conducción de vehículos y otros análogos en los supuestos en que se desarrollen formando parte del conjunto de tareas domésticas.

Este es uno de los puntos en los que encontramos discrepancias, porque las mujeres de la primera generación sí que cotizaron a la seguridad social

"Al temps se traguérem lo de empleadas de hogar, que se firmàvem unes a altres, $i$ cada una se pagava, per lo menos pa que mos quedara una pensioneta" (G.I) "Una señora que era amiga de mi prima Amparín me dijo que me apuntara a lo de la seguridad social y me apunté'. (G.II) 
Sin embargo, las mujeres de la segunda generación no se han decidido a cotizar, porque ellas consideran que no les interesa, por ello hemos hablado al inicio de economía sumergida

"jo cotisar no, perquè no me compensa" (Cotizar no me compensa) (G.II)

"a la seguritat social no estic apuntà, perquè treballe unes hores" (a la seguridad social no estoy apuntada) (G.II)

\section{Motivaciones}

Las mujeres que trabajaban en los años 30 solían trabajar como internas en casas de la ciudad de Valencia. Sus hijas, al contrario, trabajan en casas por horas Este fenómeno de las mujeres de ámbitos más rurales que se desplazaban a Valencia no era sólo un fenómeno único en la Comunidad Valenciana, sino que también hasta mitad del siglo XX ocurría en lugares como Galicia (Miras, 2005).

El trabajo como internas ahora lo desempeñan las mujeres extranjeras, Castelló señala que las autóctonas no pueden cubrir todas las vacantes que existen en el sector doméstico, por lo que las inmigrantes encuentran ahí su nicho de trabajo (Castelló, 2009).

Muchas niñas, de la primera generación, abandonaron sus casas para vivir en la que servían. Las niñas, o las fadrinas (solteras), realizaban todo tipo de trabajos hasta que al casarse dejaban el trabajo en la casa. Mucho han cambiado las cosas desde que nuestra primera generación trabajó en el sector doméstico, pero este era el trabajo más generalizado entre las mujeres en la primera mitad del siglo XX (Palacios, 2002).

"En aquell entonses no teniem res, moltes xiquetes se possaren a servir, aixina en les seues cases no els donaven a menjar i tamé ajudaven en casa. Jo me possí en Valencia, una dona que coneixia a ma mare li digué si la xiqueta se volia possar a servir, i ma mare tingué que dir que sí (...) Jo quant me vaig possar (puse) a servir tenia 14 anys". (En aquel entonces no teníamos nada, y muchas nos pusimos a servir, así en las casas nos daban de comer y ayudábamos en la economía familiar. Yo me puse a servir cuando tenía 14 años (G.I)

"Ma mare de fadrina va estar en una casa en València. En una casa molt gran, crec que per la plaça de Nàpoles, sí, per ahí va estar. Però això va ser antes de la guerra, perquè ma mare tenia 18 quant va vindre la guerra, vingué al poble. Després de la guerra també estigué una temporà en una casa, però no tant de temps. Ella sempre parlava dels senyorets" (Mi madre de soltera estuvo en una casa en Valencia. En una casa muy grande, creo que en la plaza de Nápoles, pero eso fue antes de la guerra. Después de la guerra también estuvo una temporada en una casa, pero no tanto tiempo, siempre hablaba de los señoritos) (I)

Las mujeres de la segunda generación de empleadas del sector doméstico ya no trabajan como internas. Se suelen dedicar a labores de limpieza o cuidado de niños en una jornada laboral fija, y la diferencia está en que la mayoría de ellas, según los estudios realizados, trabaja en varias casas a la vez, el trabajo no es exclusivo en una casa, como ocurría con la primera generación de internas, o como ocurre con muchas de las mujeres inmigrantes (Ioé, 2001). Según un estudio realizado por CCOO en los años 90, se estimaba 
que en España, de las mujeres que trabajan en el sector doméstico: el 70\% realizaba sus tareas por horas en más de una casa; otro $24 \%$ de las mujeres eran externas fijas, es decir, que trabajaban 8 horas en la misma casa; mientras que el restante $6 \%$ eran internas. Así pues la mayoría de mujeres vuelve a su casa después de trabajar.

"jo netege en tres cases. Vaig a dos veïnes $i$ a un altra que me va buscar la meua amiga, pequè ella no podia anar a tantes, faig unes horetes en cada casa, vaig a dies", (Yo limpio en tres casas. Voy a dos vecinas y a otra que me buscó una amiga, porque ella no podía con tantas, hago unas horas en cada casa, voy por días) (G.I)

En este caso, no se trata de mujeres que hayan dejado sus localidades natales para poder ir a trabajar lejos de sus casas. Ya no son las jóvenes internas sin hijos, sino que tienen familia propia a la que atender, convirtiéndose su vida en una doble jornada continua. De la Asunción señala que estas mujeres tienen que aguantar en las casas ajenas lo mismo que soportan en sus casas, y que sus tareas están poco definidas (De la Asunción, 1990). Lo cual significa que trabajan en función de las necesidades que tiene la familia.

"Al principio estuve un año cuidando un niño. Era un niño pequeñito de meses. Ese trabajo lo encontré porque me lo dijo mi hermana que iba una amiga suya y lo iba a dejar .Lo cuidaba durante el día hasta medio día que venía la madre. Unas veces a las 3 y otras a las 4.” (G.II)

"Ahora estoy en una casa de 7:30 a 3 de la tarde. A esa hora vuelve la madre de las niñas de trabajar. Las niñas ya son mayores. Yo las he cuidado desde que eran pequeñitas. Pero sólo tenía que llevarlas al colegio, recogerlas a la salida y darles de comer. Aparte de eso limpio la casa y eso. Llevo muchos años allí” (E. 8.)

Según Capel, en España en la década de los 30 del siglo XX trabajaban en el sector doméstico más de 350.000 mujeres (Capel, 1992), según otras cifras 400.000. Se estima que después de la guerra civil decreció el número de empleadas de hogar, a consecuencia de la situación (Bayón y Lázaro (1976). Sin embargo, en este trabajo, se hablará de las mujeres que a consecuencia de la guerra, y por sus circunstancias de falta de recursos fueron a casas a trabajar a barata el menjar, como dicen ellas. Las mujeres que se incorporaron al sector en este momento, lo hicieron en parte porque después de la guerra civil, España entró en un proceso de reruralización, lo cual suponía que las mujeres perdían ciertas expectativas de trabajo en otros campos (Ioé, 2001), fueron niñas en las que sus familias pusieron ciertas expectativas de subsistencia. Todo ello sumado al hecho de que la guerra civil dejó al país en la ruina, con un régimen autárquico que defendía unos valores familiares que poco tenían que ver con el régimen anterior (Alberdi, 1999). Además en un contexto en el que la tasa de actividad femenina era menor del 16\% (Elaboración propia a partir de datos del Ministerio de Trabajo). Señalan que durante esa época muchas de ellas trabajaban en el campo. En definitiva el contexto social no podía ser menos favorable: postguerra, reruralización y hambre

"Jo me possí a treballar quant tenia ja un poquet de coneixement, enseguida me vaig possar a servir, perquè ma mare no mos podia mantrindre, pobreta” (Yo cuando tuve 
un poco de conocimiento, enseguida me puse a servir, porque mi madre no nos podía mantener, pobrecilla) (G.I).

"Després de la guerra ací ho hem passat molt mal, i cada una feia lo que podía, jo recorde que t'abuela també anà a servir, les dos a Valencia, i quant ella se feu més major, pues temé duia coses en el tren (...)” (Después de la Guerra aquí se puso mal la cosa, recuerdo que mi abuela también fue a servir, las dos a Valencia, y cuando ella se hizo más mayor, me llevaba cosas al tren) (G.I).

En el caso de las mujeres de mediana edad, suelen empezar a trabajar en el sector doméstico después que haya habido algún problema económico o familiar que incidiera en la situación económica, o como complemento al sueldo del principal sustentador de la familia, el marido, en situaciones en las que aumentan los gastos, como puede ser la del traslado a una gran ciudad o la compra de un piso. Según un estudio realizado en la década de los 90, estas mujeres han trabajado en el sector doméstico generalmente cuando se han producido crisis en las familias, la pérdida de empleo de los cónyuges durante las crisis, etc, es un recurso rápido (De la Asunción, 1990)

"Netejant cases no mes des de que me vaig quedar viuda, antes jo no treballava, bueno, fora de casa no. Antes de casar-me estiguí en una fàbrica. Però en la pensió $i$ les xiquetes xicotetes no podía fer un altra cosa, entens?" (Limpiando casas, sólo desde que me quedé viuda, antes no trabajaba, fuera de casa no. Antes de casarme estuve en una fábrica. Pero con la pensión y las niñas pequeñas, no podía hacer otra cosa, entiendes?) (G.II).

"Ara la cosa està molt malament, hi ha moltes coses que pagar i el sueldo del meu home no es res, en això no es pot pasar, tenims moltes coses que pagar, aixina es com més diners guanye. On vaig jo en 55 anys? A mi no me volen en ningún puesto ja, $i$ això que he estat tota la vida treballant" (Ahora la cosa está mal, y hay muchas cosas que pagar, el sueldo de mi marido no da para nada, así es como más dinero gano, dónde voy con 55 años. No me querían en ningún sitio, y toda la vida trabajando) (G.II).

De esta forma observamos distintos matices en las motivaciones de las dos generaciones, por un lado, las primeras mujeres se meten en el servicio doméstico porque no les queda otra, tienen que trabajar como internas, para salvar la situación de sus familias en un contexto dominado por la destrucción y la persecución del fin de la guerra (Navarro,2004). Las mujeres que comenzaron a trabajar en la posguerra lo hicieron en un contexto de dificultades económicas generalizadas. La generación de las fadrinas (solteras) ha de incorporase al trabajo por las dificultades que sus propios padres tienen para mantener a la familia. Una de ellas, trabajó desde pequeña, y cuando después emigró a Londres, porque allí cobraba más, como nunca se casó, mantuvo el trabajo hasta que se jubiló. Esta es también la situación de muchas otras mujeres que se fueron a servir y que no se casaron, motivo por el cual no abandonaron las casas en las que prestaban sus servicios.

En el caso de las mujeres de la segunda generación, encontramos de nuevo la finalidad de aportar dinero a la economía familiar, pero, fundamentalmente de sus propias familias. En el discurso no observamos la misma angustia. Han pasado las duras épocas del régimen de la autarquía. El fin del aislamiento internacional precedió a un despegue económico entre 
finales de los cincuenta, la crisis de 1973, y la consolidación de las clases medias en España. Lo que no podemos hacer es caer en el error de pensar que las mujeres españolas no han trabajado, nunca, sabemos que desde la década de los 60 y 70, las mujeres se incorporan al mercado de trabajo, y una vez se ha conseguido entrar, es más difícil volver a salir. Aún así, las tasas de actividad de las mujeres en la primera mitad de la década de los 70 eran sólo del $26 \%$ aproximadamente (Alcaide et al., 1979). Sin embargo, en el discurso de las mujeres, no se observa que sea una alternativa momentánea para superar una situación. En el caso de la que siguió de Oper, comenta lo siguiente:

"Jo allí estava molt agust perquè em trataven com de la familia, pues se me pasava el temps, $i$ quant me vullgui donar conte, tenia 60 anys. Però després ja me vaig tornar"'(Yo allí estaba muy a gusto porque me trataban como si fuera de la familia, y cuando me di cuenta, ya tenía 60 años. Pero después ya me volví) (G.I).

\section{Condiciones laborales}

Las mujeres de la primera generación, como hemos comentado estaban como internas en casas en Valencia, y según nos cuentan, ellas no tenían ningún tipo de condición laboral, pues estaban viviendo allí y ayudaban en lo que podían, incluso se dedicaban a hacer compañía a la señoreta, que muchas veces era una mujer mayor viuda

"pues a fer lo que mos manaven xiqueta $i$ companyia" (Pues a hacer lo que nos mandaban, niña!) (G.I)

"Yo me pongo una bata, así como un vestido, pero me la he traído yo para trabajar más cómoda. A mi nunca me han dicho nada de cómo vestirme.” (G.II).

Según Castelló, el trabajo en el sector doméstico arrastra hasta hoy ciertos designios del servilismo. Las mujeres que trabajan en este sector están en régimen de (pseudo) servidumbre. Sin embargo, estas condiciones se refieren al trabajo que realizan muchas mujeres inmigrantes (Castelló, 2009). Pero también hay muchas españolas de mediana edad que se dedican al trabajo en el sector doméstico de muchas formas, como por ejemplo yendo a limpiar a casas (Freixas; Juliano, 2009).

"A mí en la casa de València no me faltaba de res, me donaven a menjar i tot, pero jo recordé que guanyava 4 chavos" (En la casa de Valencia no me faltaba de nada, me daban de comer y todo, pero ganaba 4 chavos) (G.I)

"Yo ahora cobro 580 al mes por la jornada que hago, pero yo valoro mucho más eso. El trato que me dan más que el dinero. Yo podría estar ganando más pero si no tuviera estas condiciones, no estaría con esta familia tanto tiempo.” (G.II)

Si bien hemos encontrado referencias a las mujeres de la primera generación que servían en casa de internas o que limpiaban, no hay demasiada información acerca de las mujeres de mediana edad que todavía trabajan en el sector doméstico, pero que lo hacen a tiempo parcial y en casas. Freixas y Juliano (2008) fruto de una investigación analizan los itinerarios laborales de las mujeres de la segunda generación y se ve que los trabajos que han realizado, en su mayoría están relacionados con el sector doméstico, bien de limpiadoras, o bien de cuidadoras. En la actualidad las mujeres españolas suponen el 50\% 
de las empleadas en el sector doméstico, con ello nos referimos a las mujeres que están dadas de alta en régimen del hogar (Castelló, 2009).

En una entrevista a una de las mujeres de G.I, ella nos comentaba que puede elegir las casas a las que va, y que no acepta menos de 8 euros por hora, porque tiene claro que no cotiza, y que por algún lado tiene que compensar. Sería interesante la realización de un estudio comparativo entre las condiciones de vida de las mujeres que trabajan en el sector doméstico, según su nacionalidad.

Se ha comentado que las mujeres que trabajaban de internas durante los años de la inmediata postguerra, trabajaron en la casa hasta el momento en el que se casaron, y las que no lo hicieron como hemos visto se quedaron en las casas. En cuanto a las mujeres de mediana edad que están trabajando en la actualidad en el servicio doméstico, según el estudio De la Asunción (1990), las mujeres trabajan en las casas durante periodos superiores a un año, en el caso de nuestras mujeres vemos que la continuidad también es elevada, de ahí que dijéramos al comienzo que este trabajo es más estable que muchos de los que se entienden régimen general

"Pues llevo en esta desde el año que la mayor tomó la comunión, 16 años hará en Diciembre" (G.II)

"Me faltó poco para los 15 años, me querían mucho" (G.II)

"Desde que escomenci, es que no he deixat ninguna casa, pues pac a quatre o cinc anys en cada una, per ahí estarà” (G.II)

A lo largo de los años se han producido muchos cambios en el sector en cuanto a la relación con los empleadores, esto se debe a que en la época en la que las mujeres de nuestra primera generación trabajaban como internas, las relaciones con los empleadores era distante y reflejaba la realidad de la división social en la España de la época, la sociedad de principios del siglo XX en España estaba muy estratificada, y las diferencias sociales eran muy notables (Miguel, 1998)

Esta división social se plasmaba en símbolos como los uniformes o la separación de espacios dentro de las casas. Siendo habitual, por ejemplo, que las empleadas nunca comieran en presencia de sus señores.

"Ma mare me contava que ella duia cofia i tot!!! Tu dona conte lo que les feien, ella s'arria pobreta meua!" (Mi madre me contaba que ella llevaba cofia y todo!! Date cuenta lo que les hacían, ella se reía, pobrecita mía!) (G.II)

"Esos sí que son ricos, pero ricos de cuna. No de esos que antes no han comío y ahora aparentan. Cuando se mató el primer toro de Requena se lo pusieron la cabeza en la pared. Y alrededor de la casa de Requena tenían una animalá de cepas. Ella era de Requena pero vivía en Valencia. Le gustaba mucho ir a misa. Tenían dos hijos. Su marido estaba en el ayuntamiento y era el que negociaba todo. (...) Esa mujer no sabía echar un peazo. Era señora, pero señora de cuna". (G.II)

La siguiente generación no se suele ver enfrentada a normas sociales tan estrictas. El concepto de los uniformes no es el mismo, consistiendo éstos, en ocasiones, en una bata para realizar las tareas sin ensuciarse. La división social de clases se ha modificado y desde 
la primera generación poco a poco España se ha transformado en lo que se denomina una sociedad de clases medias (Giddens, 1979).

En las mujeres que trabajan por horas, no es necesaria la diferenciación estética respecto de sus empleadoras. Esa exigencia ha perdido fuerza. Si bien Castelló (2009) nos hablaba de los residuos del servilismo, éste se sigue haciendo presente en los casos de mujeres internas y no habría que perder de vista que hoy en día se trata en su mayoría de mujeres inmigrantes, por lo que podría tenerse también en cuenta las posibles actitudes discriminatorias hacia éstas por tal condición. Sin embargo, en los casos que se han analizado, las mujeres llevan mucho tiempo en las casas, y la relación es casi familiar, de confianza entre la empleada y la empleadora. Esta apreciación la hace De Dios cuando nos explica que el trabajo en el servicio doméstico se encuentra en la frontera entre lo privado y lo público. $\mathrm{Y}$ es debido a esta circunstancia por la que muchas veces las relaciones no parecen basadas en el mercantilismo (De Dios, 2006)

"Yo como con las niñas. Hago la comida y comemos las tres juntas. Luego cuando iban todavía al colegio yo las llevaba y ya acababa. Cuando llegaba su madre a casa de trabajar, yo les había dejado la comida hecha (...) Yo no me quedo cuando ellos comen, yo ya me voy cuando llegan.”(G.II)

"en les cases que vaig he tingut molta sort. Perquè me tracten molt. Me diuen si vull tallaet i tot, pero es que jo lo que prefeisc es acavar, en este faig les meues hores i ja" (En las casas que voy he tenido mucha suerte, porque me tratan muy bien, me dicen que si quiero cortado y todo, pero es que yo prefiero acabar, y en esto hago mis horas y a casa) (G.II)

Por otra parte, como nuestro ámbito de estudio también ha estado en el medio rural, una de las mujeres limpia en dos casa de mujeres mayores. Aunque muchos ayuntamientos tienen servicios sociales de teleasistencia a personas mayores, en el caso de Benaguasil no existe esta prestación, por ello muchas mujeres contratan a sus mismas vecinas.

"pues es que jo vaig a veines de tota la vida, i es que es com familia, es una relació de casi de familia. Que son faenes que elles ja no poden fer" (Pues es que yo voy a las vecinas de toda la vida, es que son como familia, es una relación casi de familia. Que son trabajos que ellas no pueden hacer) (G.II)

La mujer "de la casa" era la encargada de organizar las tareas de las mujeres que han trabajado en el hogar, algunas no tenían muy buena relación con ellas. Este es un factor común para las dos generaciones, si bien es cierto que las relaciones como hemos visto han cambiado, sigue siendo la mujer la que se encarga de la administración de la casa.

"a mi quant vaig a la casa esta que ella es més jove, me diu lo que tinc que fer, i jo pues a la marxa” (me dicen lo que tengo que hacer y yo a la marcha) (G.II)

Diversas autoras hablan de las cadenas globales de cuidado, como Parella (2002) o Román y Martínez (2005), cuando hablan de esta tercera generación de mujeres trabajadoras del sector doméstico. Sin embargo, las mujeres de nuestra primera generación de análisis también se marcharon al extranjero, a trabajar en el sector doméstico. Durante los años de la 
postguerra mundial, y hasta bien entrados los años 80 , muchas mujeres emigraron desde España a países como Inglaterra o Francia, muchas de ellas fueron como empleadas de hogar o cuidadoras (Parella, 2002). El final de autarquía del régimen y la apertura de fronteras fue clave para el éxodo. De esta manera, fue el período que va desde 1950 a 1965 el de mayor intensidad del despoblamiento rural. (Camarero, 1991). El proceso de industrialización fue un factor determinante. Con la ruptura que la guerra civil supuso sobre esta industrialización incipiente, se dio la reruralización que hemos mencionado (Ioe, 2001) por lo que, ante la falta de alternativas, los trabajadores españoles buscaron oportunidades laborales lejos de sus lugares de origen. Los flujos migratorios del campo tras la guerra se dirigieron en un primer lugar a Europa, para tiempo después, recalar en las ciudades españolas.

"Tamé aná a Francia a una casa, estigué en unes vinyes alli pues de cuinera, que jo era xicoteta $i$ vaig anar en ella, es que ma mare se quedá viuda en dos xiquets, i ella me va dur en ella a Francia, pero no estiguérem molt de temps $i$ jo torní a la Beneficiéncia" (También fue a Francia a una casa, estuvo en unas viñas de cocinera, que yo era pequeña y me fui con ella, es que mi madre se quedó viuda cuando éramos pequeños con dos niños, y me llevó a Francia, pero no estuvimos mucho tiempo y volví a la Beneficencia) (G.II)

"En Espanya les dones pues no ho teníem molt be, $i$ a mi me digueren que en Ingleterra te possaves en una casa i cuidaves xiquets $i$ que pagaven be, i mira... Però no era fácil, tu no saps lo que tinguí que fer, els papers que teniem que demanar!!! Hasta el retor mos tenia que firmar, recollons!” (En España las mujeres no lo teníamos muy bien, y a mi dijeron que en Inglaterra te ponías en una casa y cuidabas niños y les pagaban bien, y mira... Pero no era fácil, tú no sabes lo que tienes que hacer, los papeles que teníamos que pedir!!! Hasta el cura nos tenía que firmar!!! (G.I)

Las mujeres de la segunda generación también se han movilizado para trabajar, si bien en la actualidad trabajan en sus localidades de residencia, las provincias de Madrid, Barcelona, pero también Valencia, fueron receptoras de estos flujos. Las familias se establecieron en esas ciudades comprando viviendas normalmente en los barrios obreros de la periferia, o se asentaron en los emplazamientos de la industria (Bernabé y Albertos, 1986), estas mujeres también trabajaron en el sector doméstico en la ciudad.

"Yo nací en un pueblo de Ciudad Real. Nos vinimos cuando yo tenía cinco años" (G.II)

Además de las idas y venidas del mundo rural al urbano, las idas y venidas de las mujeres se han manifestado también en las idas y venidas en el mercado laboral. Como se ha visto en las mujeres internas, ellas cuando se "hicieron mayores" que hemos visto que venía delimitado por su matrimonio, abandonaban el mercado laboral, dejaban la casa y no volvían a trabajar, si no era "preciso".

“després de la casa de Valencia... no, ja no més, perquè jo me casí” (después de la casa de Valencia... no, ya me casé y lo dejé)(G.I) 
Muchas mujeres trabajaron también en el campo, antes de mudarse a la ciudad. Realizaron trabajos que todavía hoy están poco valorados. Gran cantidad de mujeres de las dos generaciones, y también de la nuestra, han estado infravaloradas por el mercado laboral más formal, estando, como afirma, en la base de la pirámide laboral. La posición es más baja cuando combinamos el género con la clase social, las mujeres de clase trabajadora lo han tenido peor para encontrar trabajos de mejor calidad. Las historias laborales de las mujeres han estado caracterizadas por la permanencia inestable en el mercado laboral, por tener trabajos menos remunerados que los de los varones. (Prieto, 1999)

\section{La paradoja en el servicio doméstico}

Hemos dicho que los itinerarios laborales de las mujeres de las que estamos hablando tienen una permanencia inestable, es decir, que entran y salen del mercado en función de una serie de necesidades familiares. Cuando estas mujeres abandonan el sector doméstico dicen que ya no trabajan, que han dejado el trabajo, tal como se puede ver en algunos de los fragmentos descritos en el estudio. Aunque ellas siguen trabajando, pues realizan la misma tarea en su casa. Desde los años 60, las feministas están reclamando que esto sea considerado como un trabajo, al menos que se reconozca su valor. Porque muchos de los trabajos que realizan las mujeres se consideran domésticos, pero contribuyen a la economía del país de diversas formas, diversas autoras entienden que hay que cambiar la perspectiva de análisis (Rodriguez y Cooper, 2005). Desde el feminismo se está creando un modelo para calcular el peso real del trabajo doméstico en la economía (Moltó, 2007). Se estima que el trabajo doméstico que no es tenido en cuenta en el cómputo del PIB, supone una tercera parte del PIB español aproximadamente, sólo contando las mujeres que se dedican exclusivamente a realizar las tareas propias del mantenimiento de la casa, sin tener en cuenta dobles jornadas realizadas por las mujeres que sí disponen de un trabajo remunerado, mercantilizado (Candela, 2008).

\section{CONCLUSIONES}

Tabla 1 Diferencias entre las tres generaciones

\begin{tabular}{|c|c|}
\hline \multicolumn{1}{|c|}{ Primera Generación } & Segunda Generación \\
\hline $\begin{array}{c}\text { Trabajadoras desde muy jóvenes } \\
\text { (incluso niñas), ayudando a la economía } \\
\text { de sus padres. Situaciones de pobreza } \\
\text { derivadas de la posguerra }\end{array}$ & $\begin{array}{c}\text { Comienzo de la actividad laboral más } \\
\text { tardío en el sector doméstico }\end{array}$ \\
\hline Internas en las casas & $\begin{array}{c}\text { Trabajadoras a jornada. No internas. } \\
\text { Limpieza o cuidado de niños }\end{array}$ \\
\hline En ocasiones inmigrantes en Europa & $\begin{array}{c}\text { En ocasiones nacidas en ciudades y no } \\
\text { pueblos, a veces traídas de muy pequeñas }\end{array}$ \\
\hline $\begin{array}{l}\text { Relación con los empleadores } \\
\text { marcada por la distancia y la } \\
\text { estratificación en clases sociales }\end{array}$ & $\begin{array}{l}\text { Relación menos servil con los } \\
\text { empleadores }\end{array}$ \\
\hline Distinción del contratante & Necesidad social \\
\hline
\end{tabular}


Queríamos mostrar a rasgos generales las historias de estas mujeres, y su relación con el sector doméstico. Con ello no se quiere decir que todas las mujeres de la edad de nuestra primera generación hayan trabajado en el sector doméstico, una informante G.I no trabajó en el sector doméstico durante su infancia, sino que ella trabajó en el campo, otro de los trabajos comunes en la década de los 30 . El trabajo en el campo, como hemos visto estaba poco remunerado, de la misma forma que hoy también lo está.

Es muy difícil reescribir la historia laboral de las mujeres de dos generaciones como empleadas del hogar, como hemos visto, a pesar de que comparten ciertos rasgos, todas son mujeres de clase baja que trabajan por una causa coyuntural. Así que la primera de las conclusiones es que las mujeres que hemos entrevistado no veían en el trabajo en el sector doméstico un futuro socioeconómico mejor, sino más bien una ayuda para salir adelante.

En todas las historias ha quedado de manifiesto que las mujeres tienen diferentes historias de vida, con diferentes circunstancias, y que si bien hemos tratado de mostrar los rasgos generales de las historias, sería interesante dejar escrita la historia de las niñas que en los 30 se dedicaron a "servir" como lo dicen ellas. También estas historias son historias de Amor y de ternura como nos describe el Colectivo Ioé cuando habla de las empleadas domésticas.

Se han señalado algunos puntos en común, pero sin duda alguna es llamativo que, a pesar de "externalizar" el trabajo doméstico, sigan siendo las mujeres las que se encarguen de la administración del trabajo de las mujeres que están como empleadas del hogar.

Si hubiéramos dispuesto de más casos de entrevistas, habría sido interesante conocer los roles de género que se establecen entre la empleadora y la empleada en las historias de las mujeres que actualmente trabajan en el sector doméstico. En los casos que se ha analizado, se ha visto que las mujeres que trabajan en casas para mujeres mayores asumen en cierto modo el rol de hijas cuidadoras, pues son mujeres que viven solas y que necesitan más cariño que limpieza en sus casas.

Como han señalado algunas autoras, este trabajo se encuentra en la frontera entre lo público y lo privado. Es la monitorización la que le da la relación de público. Es difícil controlar el dinero que supone en economía sumergida el salario de estas mujeres, pero ellas no quieren cotizar, al menos las que hemos entrevistado, porque no les compensa económicamente. Aunque es cierto que una de ellas no conocía muy bien en qué consistía el régimen de empleadas de hogar.

Sería conveniente romper con muchas definiciones económicas que sólo tienen en cuenta el trabajo de los varones en las definiciones de empleo. Este trabajo está por lo tanto en un espacio ambiguo para muchos, pues se realiza en el domus que es espacio privado. Sin embargo, tenemos que extraer el servicio doméstico del ámbito de lo privado, porque se trata de relaciones mercantilizadas que se encuentran en situación de vulnerable, pues según hemos comprobado, las mujeres no conocen sus derechos, y tampoco las condiciones a las que se pueden acoger.

Como se ha comprobado, las mujeres que trabajaban internas en nuestra primera generación, lo hacían en casa de gente "pudiente" como nos decía alguna de ellas, sus "servicios" no eran una necesidad reproductiva en la familia. Con ello queremos decir que su mano de obra no era una cuestión de imposibilidad real de llevar a cabo el trabajo del hogar, sino más bien se trataba de una cuestión de posición social. Las casas que las contrataban lo hacían como ostentación, para distinguirse de las otras clases sociales. En la 
segunda generación, la contratación de mano de obra en el hogar se ha convertido en una necesidad de los hogares, pues el hecho de que las mujeres hayan conseguido salir al mercado laboral no ha traído consigo un reparto de las tareas domésticas, por ello se recurre a la externalización del trabajo.

Cuando hablan de sus salarios y de por qué salieron a trabajar a otras casas, hablan de sus sueldos como un complemento del salario del varón, sin embargo, hemos comprobado, que sin el salario de estas mujeres, la unidad familiar no habría salido adelante, no se habría podido hacer frente a las necesidades de subsistencia. Reformular los valores y romper con el dualismo: varón=relevante; mujer=irrelevante.

A pesar de lo que hemos comentado de la relevancia de su trabajo, el sistema social no aprecia el trabajo de las mujeres como lo ha hecho, y lo sigue haciendo, con los varones. Los trabajos de mujeres están mal pagados y se trabaja con pocas o ninguna garantía social. Aunque hemos visto que las mujeres españolas "están abandonando" el sector del cuidado remunerado, porque las mujeres migrantes son el $50 \%$ de las afiliadas a este régimen, el trabajo que abandonan las mujeres lo toman otras mujeres.

Alguna de nuestras informantes ha dicho explícitamente que tenía que elegir entre salario o prestación social, y las tres que hemos entrevistado han optado por salario.

\section{BIBLIOGRAFÍA}

ALBERDI, I. (1999): La nueva familia Española, Madrid, Taurus.

ALCAIDE, J.; FUENTES, E. y LEGARES, M. (1979): "Los problemas de empleo en la economía española y su incidencia en el medio rural", Revista de Estudios Agrosociales. no 107, pp. 9-38.

BAYÓN, M. (1976): Empleadas de hogar: trabajadoras de tercera clase, Bilbao, Zero.

BERNABÉ, J. y ALBERTOS, J.M. (2002): "Migraciones interiores en España”, Cuadernos de Geografía, vol. 39-40, p. 175.

BUSTELO, M y PETERSON, E (2005): “Conciliación y (des)igualdad. Una mirada debajo de la alfombra de las políticas de igualdad entre mujeres y hombres", SOMOS Revista de Desarrollo y Educación Popular, Primavera, $\mathrm{n}^{\mathrm{o}}$ 7, pp. 32-37.

CACHÓN, L. (2006): "Intereses contrapuestos y racismo: el incendio de los almacenes chinos en Elche”, Circunstancia: revista de ciencias sociales del Instituto Ortega y Gasset, $\mathrm{n}^{\circ} 10$.

CANALES, G. y MELIS, A. (1997): "El trabajo industrial de la mujer en la economía sumergida: las aparadoras de calzado en el bajo Segura" en Papeles de Geografía. no 25, pp. 156-196.

CANDELA, C. (2008): Motivaciones y expectativas profesionales: un análisis desde la perspectiva de género, Tesis doctoral dirigida por E. Barberá Universidad de Valencia.

CARRAQUER, P.; TORNS, T.; TEJERO, E. y ROMERO, A. (1998): "El trabajo reproductivo" Papers 55, pp. 95-114.

CASTELLÓ SANTAMARÍA, L. (2009): "La mercantilización y mundialización del trabajo reproductivo. El caso español”, Revista de Economía Crítica, no 7 , primer semestre, pp. 74-94.

CCOO (1993): Estudio del sector de servicio doméstico en Madrid, Madrid, GPS.

COLECTIVO IOÉ (1991): "Relatos desde la entraña de los hogares. Voces de inmigrantes en el servicio doméstico" en Ofrim Suplementos, no 8, pp. 37-63

- (2001): Mujer, inmigración y trabajo, Madrid, MTAS.

CORTINA, A. (1999): "La extinción de la mujer cuidadora", EL PAÍS, 23 de noviembre.

DE DIOS HERRERO, M. (2006): "El trabajo de las empleadas domésticas: entre lo doméstico (privado) y lo asalariado (público)", Aljaba (Luján), ene/dic, vol. 10, pp. 157-174.

DE LA ASUNCIÓN, R. (1990): "Servicios personales (las empleadas del Hogar)/ servicios sociales" en Zerbitzuan, $\mathrm{n}^{\circ} 12-13 / 90$. 
DE MIGUEL, J.M. (1998): Estructura y cambio social en España, Madrid, Alianza.

FREIXAS, A. y JULIANO, D. (2008): "Un sector susceptible de doble marginación: mujeres mayores que ejercen o han ejercido la prostitución", Anuario de psicología, vol. 39, $\mathrm{n}^{\circ} 1$.

GIDDENS, A. (1979): La estructura de clases en las sociedades avanzadas, Madrid, Alianza.

GONZÁLEZ SETIEN, P y otros (1992): El trabajo de las mujeres a través de la historia, Madrid, Instituto de la mujer.

JODAR. P. y ALÒS, R. (1995): "L'economia submergida en un context local. El caso de la industria tèxti de Mataró", Revista Catalana de sociología, 1/95 pp. 75-96.

MIRAS ARAUJO, J. "Rasgos básicos y transformaciones en el servicio doméstico en una ciudad periférica. A Coruña. 1900-1960”, Cuadernos de historia. 2005, vol. 27, pp. 197-221.

MOLTÓ, M. L. y URIEL, E. (2007): “¿Cuánto vale el trabajo doméstico en España?” en Cuadernos de Información económica, $\mathrm{n}^{\circ}$ 200, pp. 47-70.

NASH, M. (1983): Mujer y trabajo en España (1875-1936), Madrid, Anthropos.

PALACIO, I. (1992): Mujer, trabajo y educación: Valencia, 1874-1931, Valencia, UV.

PARELLA, S. (2002): La internalización de la reproducción, La inserción de la mujer inmigrante en los servicios de proximidad, Tesis doctoral dirigida por Carlota Solé, Universidad Autónoma de Barcelona.

PRIETO, C. (1999): "Los estudios sobre mujer, trabajo y empleo: caminos recorridos, caminos por recorrer", Política y sociedad, $\mathrm{n}^{\circ} 32$.

RODRÍGUEZ CHAURNET, D. y COOPER, J. (2005): Debate sobre el trabajo doméstico: antología, México, UNAM.

ROMÁN, M. y MARTÍNEZ PÉREZ, A. (2005): "Las cadenas globales de cuidado: un análisis sociodemográfico", Sociedad y utopía: Revista de ciencias sociales, $\mathrm{n}^{\circ}$ 26, pp. 261-278.

SÁNCHEZ, A. y otros (2003): "Empleo informal y precariedad laboral: las empleadas de hogar", Sociología del trabajo, $\mathrm{n}^{\mathrm{o}} 47$.

SANFELIU, L. (2005): Republicanas. Identidades de género en el Blasquismo (1895-1910),Valencia, PUV.

SARASÚA, C. (1994): Criados, nodrizas y amos: el servicio doméstico en la formación del mercado de trabajo madrileño, 1758-1868, Madrid, Siglo XXI.

SENNETT, R. (2000): La corrosión del carácter: las consecuencias personales del trabajo en el nuevo capitalismo, Barcelona, Anagrama.

\section{Breve currículo:}

\section{Cristina Benlloch Doménech}

Licenciada en Sociología por la Universidad de Valencia con Premio Extraordinario. Máster en Género y Políticas de Igualdad. Becaria FPI del Departamento de Trabajo de Social y Servicios Sociales de la Universidad de Valencia. Estuvo de Becaria en el Instituto Nacional de Estadística en el año 2009, en la Subdirección de Población e Inmigración. Forma parte de la comisión de Género de la ONGD Veterinarios Sin Fronteras desde el 2008. Evaluadora externa en artículos sobre género.

\section{Cristina Pérez Pérez}

Licenciada en Ciencias Políticas y de la Administración por la Universidad Cardenal Herrera CEU. Actualmente cursa sus estudios de postgrado en el Institut Universitari d'Estudis de la Dona donde termina el Máster de Género y Políticas de Igualdad especializándose en diseño y evaluación de políticas públicas desde una perspectiva de género. Su experiencia laboral se divide entre el ámbito privado, concretamente en el sector terciario avanzado o de consultoría, y el público, con su actual participación como agente de igualdad en la elaboración de Planes de Igualdad para diferentes Ayuntamientos de la Comunidad Valenciana. 